\title{
EFICÁCIA DAS ABORDAGENS FISIOTERAPÊUTICAS NO TRATAMENTO CONSERVADOR DE HÉRNIA DE DISCO: REVISÃO DE LITERATURA
}

\begin{abstract}
Khrislayne Gonçalves Casemiro ${ }^{1}$
Kauara Vilarinho Santana Vieira ${ }^{2}$

RESUMO: A hérnia de disco (HD) ocorre pela ruptura do anel fibroso, em consequência do deslocamento do núcleo intervertebral, causando grandes dores na coluna, podendo desencadear problemas na postura, diminuição dos movimentos e da flexibilidade. São fatores de risco: causas posturais, desequilíbrios musculares e possivelmente, a influência genética. Desta forma, o objetivo geral desta pesquisa foi verificar a eficácia entre os vários métodos de tratamento fisioterapêutico conservador na hérnia de disco lombar (HDL). Para alcançar esse objetivo, utilizou-se a pesquisa documental, analisando referenciais já existentes que contribuem para a discussão sobre o tema aqui analisado. Ao final pode-se concluir que o tratamento conservador aplicado de forma correta com o auxílio de um diagnóstico precoce tem uma probabilidade maior de resultados satisfatórios, dispensando a intervenção cirúrgica sem maiores prejuízos ao paciente, devolvendo-lhe a qualidade de vida.
\end{abstract}

Palavras-chave: Hérnia de Disco. Dores na Coluna. Tratamento Conservador. Reabilitação.

ABSTRACT: Herniated disc (HD) occurs by the rupture of the fibrous ring, as result of the displacement of the intervertebral nucleus, causing great pain in the spine, and can trigger problems in posture, decreased movement and flexibility. Risk factors are: postural causes, muscular imbalances, and possibly, genetic influence. Thus, the general objective of this research was to verify the effectiveness between the various methods of conservative physiotherapy treatment in herniated lumbar disc (HDL). To reach this objective, documentary research was used, analyzing existing references that contribute to the discussion about the theme analyzed here. In the end it can be concluded that the conservative treatment applied correctly with the help of an early diagnosis has a higher probability of satisfactory results, dispensing with surgical intervention without further harm to the patient, giving him back the quality of life.

Keywords: Herniated Disc. Pain in the spine. Conservative treatment. Rehabilitation.

\footnotetext{
Acadêmica do Curso de Fisioterapia, Faculdade UniBrás - Unidade Rio Verde. Email: khrislaynegc@gmail.com.

2 Orientadora, Fisioterapeuta e Professora Especialista na Instituição de ensino UNIBRÁS, Email: kauaravvieira@gmail.com.
} 


\section{INTRODUÇÃO}

O disco intervertebral é uma estrutura única, com capacidade de absorver choques e resistir à deformação induzida pela carga. É composto por uma estrutura externa rígida, designada anel fibroso, sendo uma estrutura interna gelatinosa, chamada núcleo pulposo (CAIRES; ALVES, 2018).

A hérnia discal (HD) é o processo de protrusão do núcleo do disco intervertebral através de rupturas em suas fibras. Pode estar relacionada tanto a traumas quanto a estresse, geralmente em discos que demonstrem sinais de degeneração prévia (GARCIA, 2018).

A coluna lombar é a região mais acometida pela herniação do disco intervertebral que, por sua vez, pode originar a lombalgia, seguida de dor ciática pura (SUSSELA et al., 2017). Diante disto, várias intervenções têm sido relatadas com intuito de reduzir os impactos desta patologia na vida dos pacientes. Porém, ainda é desconhecida uma intervenção de eficácia específica para as pessoas que sofrem dessa patologia (HARRINSON; OAKLEY, 2017).

Pacientes com hérnia de disco padecem em sua qualidade de vida, afastam-se de suas atividades e aumentam os custos aos cofres públicos e muitos desses pacientes não conseguem submeter-se à cirurgia (HARRINSON; OAKLEY, 2017).

Geralmente os pacientes surgem aos consultórios com queixas de dor intensa com irradiação para o membro cuja raiz nervosa é afetada, com fraqueza muscular seguida de parestesia e/ou paresia do membro acometido. Outros sintomas são rigidez de nuca e parestesias em pés e mãos. Na região cervical, a dor inicia no pescoço e geralmente irradia para os membros superiores, enquanto na região lombo- sacra, a dor tem início em região lombar, podendo se irradiar para nádega, coxa e joelhos. A dor pode ser aguda com piora ao esforço físico, geralmente em jovens, ou permanente de fraca intensidade, mais comumente em idosos (SUSSELA et al, 2017).

É essencial um bom diagnóstico para poder prosseguir com o tratamento correto da hérnia de disco, sendo necessários pedidos de exames complementares, como por exemplo, a ressonância magnética da coluna vertebral para se verificar o local da lesão e o aspecto em que se encontra a hérnia de disco e a evolução da patologia. O tratamento da alteração no 
disco intervertebral é inicialmente conservador e, em alguns casos, são primordialmente cirúrgicos (CAIRES; ALVES, 2018).

O tratamento conservador, ou não cirúrgico, é recomendado como primeira linha de tratamento e engloba a utilização de medicamentos anti-inflamatórios e analgésicos, a realização de fisioterapia, acupuntura e trações, o uso de colares de imobilização e a adesão a intervenções como as injeções foraminais de corticosteroides. Essas injeções, também conhecidas como bloqueios neurais, possibilitam alívio da dor de forma segura e eficaz, com raros eventos adversos descritos. Já o tratamento cirúrgico é indicado quando não se há uma boa adaptação e evolução ao tratamento conservador baseados na utilização de medicamentos, eletroterapias e terapias manuais (OLIVEIRA et al., 2019).

Partindo dessa premissa, entra a fisioterapia, que tem um papel importante na reabilitação dos pacientes com hérnia de disco, tendo vários métodos que auxiliam no tratamento e, disponibiliza de recursos e terapias que podem ser utilizados, sendo priorizado sempre aquele tratamento que der um melhor resultado para o paciente de forma individualizada e humanizada. Deve-se lembrar que cada organismo responde de maneira diferente ao tratamento (LOIOLA et al., 2017).

Nesse contexto, a escolha desse tema justifica-se pela importância do tratamento conservador para HDL diante das diversas sequelas geradas por procedimentos cirúrgicos. Após o diagnóstico da hérnia de disco, é importante averiguar qual o tratamento deverá ser feito com o uso de alguns medicamentos prescritos pelo médico especialista e qual tratamento fisioterapêutico com sessões de fisioterapia convencional podem contribuir para promover esta patologia.

O intuito do tratamento cirúrgico, é a melhora da dor, a descompressão e a estabilização mecânica da coluna vertebral, mas através das revisões de literaturas, percebeuse que o processo cirúrgico não é o principal procedimento adotado nesses casos. Apenas uma porcentagem mínima dos casos de pacientes com HDL necessita de cirurgia, caso o tratamento conservador não tenha efetividade ou quando houver persistência ou progressão do déficit neurológico e aumento de crises incapacitantes

Diante da necessidade de encontrar soluções para esse problema tão comum na população, este estudo objetivou realizar uma revisão de literatura para verificar a eficácia 
da fisioterapia sobre a abordagem conservadora no tratamento de hérnia de disco (HD) por meio de intervenções fisioterapêutica e técnicas direcionadas. Assim, busca-se responder, com base na produção científica publicada em periódicos indexados, a seguinte pergunta norteadora da investigação: Quais as técnicas e ações desenvolvidos pelo fisioterapeuta pode apresentar maior efetividade quanto ao tratamento conservador de hérnia de disco lombar (HDL)?

\section{Metodologia}

O método empregado para a realização deste estudo foi uma revisão da literatura baseada em materiais encontrados nas seguintes bases de dados: BVS (Biblioteca Virtual em Saúde), SCIELO (Scientific Electronic Library Online), LILACS (Literatura Latinoamericana e do Caribe em Ciências da Saúde) e PubMed. Foi feita a análise qualitativa e revisões sistemáticas em livros e artigos publicadas nos últimos io anos (2011-2021) sobre hérnia de disco, a fim de elucidar os aspectos determinantes para a aquisição de conhecimentos sobre o tema estudado. Optou-se por estas bases de dados e biblioteca por entender que abrangem a temática abordada.

A busca ocorreu no período entre julho e setembro de 2021, sendo usada como estratégia de busca os seguintes descritores: Fisioterapia, Hérnia de Disco, Dor Lombar e Tratamento Conservador. Outro critério também utilizado foi o ano de publicação dos estudos e artigos (2011-202I), artigos que apresentavam pesquisas originais, metanálises, livros digitais e publicações na Língua Portuguesa. Os estudos duplicados ou sem critérios de fontes de dados e textos não científicos, tais como: blogs, sites não indexados ou sem vínculo científico, foram descartados por não atender aos critérios de busca.

\section{Fundamentação teórica 3.I Hérnia de disco (HD) e sua fisiopatologia}

A hérnia de disco é uma frequente desordem músculo esquelética, responsável pela lombociatalgia. A expressão hérnia de disco é usada como termo coletivo para descrever um processo em que ocorre ruptura do anel fibroso, o que permite que o fluido interno do disco interna (o núcleo pulposo) possa escapar e comprimir a raiz nervosa espinal ou a medula, resultando em dor nas costas e outros sinais de incômodo de raiz nervosa, como a perda 
sensorial ou motora e dor. No caso da coluna isso acontece devido ao rompimento do anel fibroso, que acaba permitindo que o núcleo se projete para fora, gerando uma protuberância que pode comprimir as estruturas vizinhas (KUTZKE et al., 2016).

A hérnia discal lombar é uma manifestação comum da doença degenerativa discal tem seu pico de incidência entre a 3 e 4 décadas de vida, a maioria das HD são mais acometidas na são a coluna lombar, entre as vértebras lombares $\mathrm{L}_{4}-\mathrm{L}_{5}$ e $\mathrm{L}_{5}$ - $\mathrm{S}_{\text {I }}$ e a coluna cervical, $\mathrm{C}_{4}-\mathrm{C}_{5}, \mathrm{C}_{6}-\mathrm{C}_{7}$ e $\mathrm{C}_{7}-\mathrm{T}_{\mathrm{I}}$. Os principais sintomas são a lombalgia, a lombociatalgia, a ciática isolada e a síndrome da cauda equina e em alguns indivíduos podem ocorrer de maneira assintomática. Alguns estudos reportaram uma forte predisposição genética na etiologia da degeneração do disco vertebral (HERDMAN, 2015).

Estima-se que 2 a $3 \%$ da população possam ser afetados, com prevalência de $4,8 \%$ em homens e 2,5\% em mulheres, acima de 35 anos. Por ser tão comum, chega a ser considerada um problema de saúde mundial, em decorrência de incapacidade que gera. Os homens geralmente estão entre os mais acometidos, devido a esforços repetitivos, trabalhos que exigem um grau de força maior, entre outros (KUTZKE et al., 2016).

O mecanismo de lesão da hérnia de disco, normalmente caracteriza-se pela rotação e inclinação de tronco. Dessa forma, o esforço e sobrecarga gerados no disco intervertebral fazem com que haja a compressão mecânica da raiz nervosa. Por isso, podem ocorrer isquemias e fenômenos que sensibilizam a membrana à dor (GODINHO et al., 20II).

Sobre os tipos de hérnia, Souza e Silva (2019), salienta elas são classificados dependendo da distância em que se encontra a hérnia, ou seja, quando verificada a longitude da altura da mesma em relação a sua base. Sendo assim, pode-se dizer que a protusa é um início deste problema; já quando há um afastamento de um trecho do disco do anel fibroso para o lado externo, causando uma deformação é chamado extrusão e por fim o tipo sequestrado, quando a hérnia já ultrapassa de forma exagerada esse limite, sem manter uma continuidade.

O segundo tipo apresentado, quando a mesma está de forma posterolateral, pode gerar uma compressão em um conjunto de nervos chamado cauda equina, ou também de cone medular, e caracterizar uma síndrome de mesmo nome. Com isso, o paciente irá sentir 
alguns sintomas como dor radicular, anestesia, perda de força de ambos os lados, e dentre outros sintomas como a alteração intestinal, assim como urinária (SUSSELA et al., 2017).

A HD causa uma compressão nervosa na raiz descendente, entretanto, a hérnia quando é foraminal e extraforaminal não faz a compressão da mesma, e sim da raiz que sai daquele forame. Decerto que em cada raiz vão se apresentar de maneira diferentes (GODINHO et al., 20II).

$\mathrm{Na}$ L3 causa uma alteração na sensibilidade (parestesia) na parte medial da coxa, com diminuição da força muscular do quadríceps, assim como diminuição no reflexo patelar. Uma vez que na raiz $\mathrm{L}_{4}$ tem perda de sensibilidade na porção interna da perna, modificação na força do tibial anterior, e restrição do reflexo patelar. Por certo, a raiz L5 causa parestesia na lateral da perna, paresia no extensor longo do hálux e os reflexos mantém-se normais. Por fim na Si promove parestesia na posterior da perna e ou lateral do pé, além de diminuição da força muscular do gastrocnêmio, sóleo e fibular, com alteração no reflexo calcâneo (PUDLES; DEFINO, 2014).

A HD ela pode ter uma base mais alargada que compreende uma porção entre $25 \%$ e $50 \%$ do seu tamanho, assim como quando é focal, ou seja, menor quando comparada a circunferência no todo do disco, sua dimensão é abaixo de 25\% (SUSSELA et al., 2017).

Em relação a estrutura do anel fibroso, a HD pode ser qualificada como contida, pelo fato de ser coberta pelo ânulo externo, ou também como não contida, quando não tem essa cobertura. Quanto a sua localização, ela pode se localizar em diversas regiões mais centralizada, posterolateralizada, e também foraminal e extraforaminal, ademais, consideradas quanto o seu conteúdo e inclusive pela sua porção (OLIVEIRA; ODA, 20I5).

\subsection{Anatomia da coluna lombar}

A coluna vertebral constitui o eixo ósseo do corpo composto por vinte e seis ossos e está constituída de modo a oferecer a resistência de um pilar de sustentação, mas também a flexibilidade necessária à movimentação do tronco (SCHOELLER, 2016).

A coluna vertebral do adulto apresenta quatro curvaturas, sendo duas anteriores, na região cervical e lombar, denominadas lordoses, e duas posteriores, nas regiões torácica e sacral, denominadas cifoses. A coluna vertebral estabelece e mantém o eixo longitudinal do 
corpo. Como é uma haste multiarticulada, os movimentos da coluna vertebral ocorrem como resultado de movimentos combinados das vértebras individuais (GODINHO et al., 20II).

A coluna lombar $\left(\mathrm{L}_{1}\right.$ a $\left.\mathrm{L}_{5}\right)$ inicia na base da coluna torácica e termina no sacro. É constituída por cinco vértebras grandes. A região lombar é a que suporta a maior carga e conservar grande flexibilidade as quais são conectadas por ligamentos e discos intervertebrais. Por isso, os discos cartilaginosos entre as vértebras lombares inferiores são locais comuns de lesões e processos patológicos. Na coluna convivem 3 tipos de estruturas: uma parte óssea, os componentes articulares não-ósseos (ligamentos e articulações) e os nervosos (medula, raízes e envoltórios) (SCHOELLER, 2016).

De maneira geral, as articulações da coluna vertebral são compostas pelos corpos vertebrais com discos intervertebrais e ligamentos, com funções antagônicas de estabilização, absorção de impacto e movimento. Os discos intervertebrais estão situados entre corpos vertebrais sucessivos a partir da segunda vértebra cervical de cima para baixo. São 23 discos em toda coluna. Ele é formado pelo núcleo pulposo (massa central gelatinosa) ausente da articulação de $\mathrm{C}_{1}$ e $\mathrm{C}_{2}$, anel fibroso (porção ligamentar) e pelo platô vertebral que é formado por cartilagem hialina onde o disco se insere. O disco serve, pela sua estrutura, de amortecedor hidrodinâmico entre os corpos vertebrais (SANTOS; 2018).

O núcleo repousa sobre a parte central do platô vertebral ou placa terminal, que é a parte mais externa do disco e tem um espessamento ósseo em sua periferia, o anel epifisário, que é deficiente na parte posterior. $\mathrm{O}$ anel fibroso é composto por fibras obliquas que se cruzam, correndo entre os corpos vertebrais adjacentes e firmemente ligados à circunferência das placas terminais (GODINHO et al., 20II).

De acordo com Santos (2018), a obliquidade e a elasticidade das fibras anulares permitem a flexão, extensão e a rotação. Sendo que a rotação da coluna vertebral é restrita pelo limite da extensibilidade das fibras anulares. $\mathrm{Na}$ coluna lombar praticamente não há rotação. Na coluna dorsal, ao contrário da lombar, as rotações chegam ao máximo nas suas amplitudes e a fisiologia do anel fibroso é exatamente absorvê-las.

A pressão no interior do núcleo separa as vértebras uma da outra e as fibras anulares puxam-nas uma para perto da outra. Quando uma pressão importante é exercida no eixo da coluna vertebral (como o peso do corpo em posição de pé), a água e produtos de excreção 
contida na substância gelatinosa do núcleo saem através de orifícios do platô vertebral em direção ao centro dos corpos vertebrais. Se esta pressão for mantida durante todo o dia, no final desse dia o núcleo estará menos hidratado que durante a manhã, logo, o disco diminuiu a sua espessura (SCHOELLER, 2016).

\subsection{Principais alterações funcionais decorrentes da hérnia de disco}

A hérnia de disco surge como resultado de diversos pequenos traumas na coluna que vão, com o passar do tempo, lesando as estruturas do disco intervertebral, ou pode acontecer como consequência de um trauma severo sobre a coluna. Podem ser assintomáticas ou sintomáticas que vai depender da localização, do tamanho, do tipo e do grau de envolvimento radicular (ALVES; MEVES, 2014).

De acordo com Carlos (2012), os indivíduos que, durante o trabalho, realizam rotação ou flexão do tronco carregam materiais pesados ou se submetem a fortes vibrações no corpo, aumentam as chances de desenvolver lesões nos discos intervertebrais e, consequentemente, uma hérnia de disco lombar.

A coluna é o centro de equilíbrio do sistema musculoesquelético do ser humano.

Muitas lesões da coluna vertebral são atribuídas ao desequilíbrio e desalinhamento desta estrutura, ou seja, a má postura (SIQUEIRA et al., 20II).

Fatores hereditários são os que mais provocam hérnia de disco, no entanto traumas de repetição no trabalho e no esporte, traumas direto, o fumo e a idade avançada também são motivos de lesões degenerativas (SCHOELLER, 2016).

De acordo com Siqueira et al. (2011), o sedentarismo é um fator determinante para dores nas costas oriundas da hérnia de disco e de outras doenças, pois as pesquisas comprovam que a atividade física qualitativa para coluna é um fator de extrema importância para melhora e prevenção das dores nas costas. Mas há outros fatores ocupacionais associados a um risco aumentado de incidência de hérnia de disco estão: (a) trabalho físico pesado; (b) postura de trabalho estática; (c) inclinar e girar o tronco frequentemente; (d) levantar, empurrar e puxar pesos; e (e) trabalho repetitivo. 


\subsection{Diagnóstico}

O exame neurológico é fundamental em todos os pacientes com suspeitas de HDL. A sensibilidade é difícil de ser graduada, sendo em geral registrada como normal, diminuída ou aumentada. O exame da força deve ser realizado de forma padronizada testando-se o movimento em vez de músculos específicos e é graduado de zero a cinco, sendo grau cinco força completa contra resistência. Os reflexos são testados bilateralmente e graduados também como normais, diminuídos ou ausentes (NUNES, 2016).

O diagnóstico da hérnia de disco pode ser feito pelas manifestações clínicas em cerca de $90 \%$ das vezes. Portanto, os exames subsidiários apenas nos auxiliam para determinar o local exato e a extensão do prolapso, para afastar outras causas de lombociatalgia e para nos guiar na terapia a ser instituída (SOUSA; SILVA, 2019).

A radiografia da coluna (raio $\mathrm{X}$ ), por ser um exame amplamente disponível e de baixo custo, pode ser o primeiro exame no estudo das dores lombares. O objetivo do raio $\mathrm{X}$ é a procura de alterações degenerativas que podem indicar a presença de hérnia de disco, porém esses achados são inespecíficos e não avaliam a HD propriamente dita (PEREIRA, 2018).

A tomografia da coluna é um exame com maior acurácia em relação ao raio $\mathrm{X}$, pois analisa com maior detalhe os corpos vertebrais e articulações, definindo melhor as alterações degenerativas e podendo diagnosticar hérnias mais evidentes. Porém ainda apresenta menor sensibilidade para avaliação pormenorizada do tamanho da hérnia, das raízes neurais e do canal vertebral (PEREIRA, 2018).

A ressonância magnética da coluna é o exame de maior sensibilidade e acurácia para o diagnóstico das hérnias de disco, pois apresenta uma ótima diferenciação das estruturas de partes moles, como o disco intervertebral, as raízes neurais e o canal vertebral. Sendo o melhor exame para o diagnóstico, para analisar o tipo e extensão da hérnia, bem como para a definição do tratamento (VIEIRA, 202I).

Além dos exames discorridos, há também a eletroneuromiografia, o único exame disponível para avaliar diretamente a integridade fisiológica das raízes nervosas. Sua sensibilidade é comparável à da tomografia computadorizada e da ressonância magnética. No entanto, estima-se que sua especificidade seja maior. A eletroneuromiografia combinada 
aos métodos de imagem é útil para identificar qual a raiz envolvida em paciente com anormalidades em múltiplos níveis vertebrais, e se as anormalidades encontradas são funcionalmente relevantes. Além destas situações, o exame auxilia no diagnóstico diferencial com lesões de plexo ou nervo periférico (PINTO, 2016).

Esta avaliação é denominada dinâmica, obtida com a cervical em posição de hiperflexão e hiperextensão com a finalidade de identificar se esta instabilidade ocorre por doença degenerativa ou artropatias inflamatórias (artrite reumatoide), além de eventual instabilidade aguda pós-traumática e pode estar comprometida em virtude da possível presença de lesão neurológica. Durante as manobras de posicionamento podemos desestabilizar ainda mais o local, sendo necessário substituir o exame de raio $\mathrm{X}$ pela ressonância magnética. As radiografias de incidência básica são anteroposteriores (AP), perfil e as oblíquas (com rotação de 45 graus). As incidências AP e oblíqua têm como uma de suas finalidades avaliar as articulações uncovertebrais, em relação aos forames de conjugação neurais (saída do tronco nervoso) (PINTO, 2016).

Qualquer que seja o motivo da hérnia discal, é devido à alteração degenerativa do anel. A hérnia discal ocorre com maior frequência no adulto jovem que no idoso. Clinicamente as hérnias discais consiste de dor lombar e lombociatalgias (sintoma de dor que irradia para os membros inferiores) (ALVES e MEVES, 2014).

\subsection{Tratamento conservador de hérnia de disco}

Atualmente, há diversos tratamento disponíveis que podem ajudar no alívio das dores de quem sofre com a $\mathrm{HD}$, sem a necessidade de cirurgias mais agressivas, pois a fisioterapia, como tratamento conservador, atua na hérnia discal com técnicas de terapia manual, decoaptação geral e trações axiais, utilização do períneo para reposicionamento sobral, aberturas manuais para libertação do espaço lesado, melhora da qualidade do movimento de inclinação anterior do tronco, aumento da sustentação muscular e alongamentos musculares diminuindo secundariamente a dor, a rigidez e o espasmo (PUDLES; DEFINO, 2014).

O tratamento conservador para hérnia de disco (fisioterapia) vai depender de qual estágio a doença se encontra. Sussela et al (2017) divide o tratamento conservador em três 
fases: (a) Fase Aguda (com repouso absoluto por 3 dias na posição mais confortável e uso de anti-inflamatório); (c) Fase Pós-Aguda (com técnicas fisioterápicas); e (c) Fase Tardia (o paciente apenas apresenta desconforto com a manutenção da elasticidade e tônus muscular associada aos cuidados posturais).

Métodos fisioterapêuticos como tração, aplicação de ultrassom e laser de baixa intensidade, mostraram-se eficientes no tratamento agudo das hérnias discais lombares para restaurar a força muscular e a flexibilidade. Se, no entanto houver recorrência da enfermidade, dores e desconfortos, os exercícios deverão ser descontinuados e reiniciados somente após a remissão dos sintomas. Entretanto quando há sinais de perda da força ou sensibilidade, o tratamento cirúrgico deve ser indicado (POWERS; HOWLEY, 2017).

Powers e Howley (2017), alertam ainda que os exercícios de flexão estão sumariamente contraindicados nas hérnias discais agudas e nas protrusões discais difusas acentuadas, com dor grave e canal estreito. Já os de extensão estão indicados nas protrusões difusas e focais do disco, fora do período agudo doloroso, com cuidados especiais em caso de artrose zigapofisária.

Nesse contexto, a figura do profissional fisioterapeuta é muito importante, pois ele estabelece junto ao paciente objetivos que promovam a analgesia, fortalecimento da região e estabilização vertebral do local onde a hérnia de disco está localizada com o objetivo de impedir que a doença progrida evitando a formação de novas hérnias (CARLOS, 2012).

\section{5 Tratamento fisioterapêutico 3.5.I Método: hidroterapia}

O termo hidroterapia se aplica a utilização da água sobre a superfície corporal onde se busca as ações mecânicas e térmicas decorrentes da pressão, do calor ou frio da água sobre o organismo, assim como na imersão onde se faz proveito dos efeitos da flutuação e pressão hidrostática. As propriedades físicas da água e os efeitos oriundos da imersão fornecem uma série de respostas de valor terapêutico ao organismo (COELHO et al., 2012; JAKAITIS et al., 2016).

A utilização da hidroterapia no tratamento da hérnia de disco lombar, para os pacientes com HDL que não conseguem realizar exercícios no solo, acarreta uma série de benefícios aos pacientes submetidos a este recurso da fisioterapia. Através da ação dos efeitos 
das propriedades físicas da água na piscina terapêutica, a hidroterapia diminui os níveis de dor, reduz as forças de compressão articular, diminuindo assim a pressão intradiscal e propicia um grande relaxamento muscular. Há uma percepção de ausência de peso no ambiente aquático, o que parece reduzir consideravelmente a proteção muscular do corpo, resultando na diminuição do espasmo muscular (OLIVEIRA et al., 2019).

\subsubsection{Método: Mackenzie}

O Método Mckenzie é uma técnica terapêutica baseada na avaliação da dor, na resposta sintomática ou diminuição da deformidade tecidual, utilizando os movimentos repetidos em amplitude máxima, posições sustentadas e mobilizações do próprio paciente, buscando alívio da dor e a recuperação da função. Nesse método utiliza-se tanto exercícios de extensão quanto de flexão (MENDONÇA; ANDRADE, 2or6).

O Dr. Robin Mckenzie acreditava que as dores lombares tinham três mecanismos responsáveis: ( $\mathrm{I}^{\mathrm{a}}$ ) Síndrome de Postura, causada por uma deformação mecânica dos tecidos moles adjacentes aos segmentos vertebrais; (2 $\left.2^{\underline{a}}\right)$ Síndrome de Disfunção, causada por um encurtamento ou aderência tecidual causada pela má postura ou por contratura do tecido fibro-colagenoso desenvolvido após um trauma; e (3 $\left.3^{\underline{a}}\right)$ a Síndrome do Desarranjo causada por um deslocamento do disco intervertebral (ALECRIM, 20I4).

Nas fases mais avançadas do tratamento, é introduzido a flexão com a finalidade de reorganizar o colágeno que é depositado de forma desordenada no anel fibroso. Mckenzie segue as três fases do processo de recuperação do disco através de seu método: (a) o processo natural de cura, (b) o mecanismo autoselante e (c) recuperação cartilaginosa. Quando bem compreendida e aplicada, é muito eficaz (OLIVEIRA; ODA, 2015).

\subsubsection{Método: osteopatia}

A osteopatia é um método que possibilita fazer o diagnóstico palpatório de bloqueios tissulares e articulares, em geral, chamados de lesões ou disfunções, necessitando utilizar manipulações, onde realiza-se um alongamento permanentemente nos tecidos moles que possam estar restringindo a mobilidade através da utilização de forças externas específicas, utilizada manualmente. A massagem ativa a circulação no local da dor e remove 
os detritos possibilitando melhor ação muscular e na movimentação corporal (BORTOLAZZO et al., 2015; PERES et al., 2011).

Sua metodologia baseia-se no conhecimento aprofundado da anatomia, fisiologia e patologia do corpo humano permitindo identificar e tratar disfunções de mobilidade dos tecidos corporais. Ela é um meio de diagnóstico e tratamento que utiliza recursos manuais para uma abordagem terapêutica do corpo e suas dores. Por ser uma técnica de alta velocidade baixa amplitude (AVBA) têm se mostrado de grande valia e eficácia na abordagem fisioterapêutica, restaurando a função articular normal e promovendo um equilíbrio da função muscular (SILVA et al., 2orI).

\subsubsection{Método: fisioterapia convencional}

A fisioterapia convencional é definida como a intervenção que visa modificar déficits nas estruturas e funções corporais. A fisioterapia convencional geralmente inclui exercícios de força, alongamento, equilíbrio, treinamento aeróbio, modulação do tônus, e aplica os princípios baseados na abordagem do neurodesenvolvimento. Essa abordagem considera o desenvolvimento e a maturação do sistema nervoso central como a base para as técnicas de intervenção. Existem três princípios fundamentais para esta abordagem que inclui a facilitação do movimento e a facilitação ou inibição de padrões patológicos (PERES et al., 20II).

De acordo com Nogueira (2016), para alcançar os fins e objetivos propostos, aplica técnicas com fins de reabilitar e reduzir a dor do paciente. Dentro do seu leque de tratamentos, realiza-se a termoterapia (utilizando tanto o calor, quanto o frio); fototerapia (procedimentos com luz); mecanoterapia (emprego de aparelhos mecânicos); eletroterapia (uso de cargas elétricas) e a massoterapia (terapias manuais).

Muito embora a fisioterapia convencional proporciona tratamento eficazes para a HDL, o paciente necessita continuar dando manutenção aos ganhos alcançados durante o tratamento e estes podem ser supridos também através das outras técnicas/métodos, capaz de conferir a diminuição do quadro álgico, o aumento da estabilidade e da mobilidade à coluna vertebral, melhora da funcionalidade e qualidade de vida do indivíduo. Toda 
fisioterapia convencional com três objetivos semelhantes: a analgesia, o alongamento e o fortalecimento muscular (BARBOSA; SILVA, 202I).

\subsubsection{Método: mobilização neural}

A mobilização neural é um recurso terapêutico para as diversas disfunções do tecido neural e do sistema musculoesquelético. No entanto, é uma técnica ainda pouco conhecida e explorada pelos profissionais da área da saúde no Brasil. O objetivo desta técnica é melhorar a neurodinâmica, restabelecendo a homeostasia dos tecidos afetados nas síndromes compressivas e tem sido abordada como método terapêutico no alívio da dor, para o ganho de amplitude do movimento e no tratamento de patologias que acometem as raízes nervosas e suas extremidades, com a finalidade de desenvolver elasticidade no sistema nervoso e promover uma melhor recuperação dos movimentos (BRANCO, 2019; LOPES et al., 20II).

A mobilização neural em quatro categorias: (a) indireta, quando são aplicados as estruturas algumas oscilações próximo ao tecido comprometido; (b) direta, quando os nervos periféricos são tensionados por alguns movimentos oscilatórios através de articulações eu estruturam o trajeto nervoso; deslizante, quando a mobilização existe sem causar aumento de tensão; (c) tensionante, mobiliza-se simplesmente aumentando e diminuindo a tensão no trato neural e (d) deslizante, em que se mobiliza o trato neural sem provocar o aumento da tensão (BRANCO, 2019).

Quando os testes neurodinâmicos (ou testes neurais) forem realizados em pacientes com hérnia discal o fisioterapeuta deverá estar atento a todo o trajeto do nervo e aos sinais referidos pelo paciente, interpretando-os de acordo com o quadro clínico do paciente, uma vez que nem todos os sintomas que aparecem nos testes neurais são patológicos (BUTLER, 2015).

\subsubsection{Método: acupuntura}

O corpo é dotado de energias que devem estar em equilíbrio e em harmonia. Dependendo do caso, pode ter resultados satisfatórios como na dor aguda, porém os resultados mais fidedignos são nas dores crônicas (WEN, 20II). 
A acupuntura é muito usada no tratamento da HDL com o objetivo de controlar a dor, pois reduz as contrações musculares, desbloqueando as tensões em torno da HD. Com isso, ajuda no relaxamento total e na rápida recuperação do paciente (CANÇADO, 2017).

A acupuntura tem apresentado bons resultados, uma vez que seu efeito parece estar relacionado à liberação de vários neurotransmissores que, por sua vez inibem ou excitam as sinapses, proporcionando significante melhora dos sintomas apresentados em curto espaço de tempo. Em vista dos resultados promissores que têm sido obtidos com o uso da acupuntura no alívio da dor, há a sugestão de se explorar mais seu uso (YAMAMURA; YAMAMURA, 2015).

\subsubsection{Método: pilates}

Com base na crença que o ser humano é uma unidade integrada entre corpo e mente o pilates é um método de exercício que traz uma boa qualidade de vida. Qualquer movimento passa pelo cérebro, logo é um exercício entre mente e o controle corporal. O condicionamento físico, mental e uma postura ereta são combinações que o pilates incorpora. Para estabilizar o tronco precisa-se dar ênfase na musculatura profunda do corpo, sendo este o foco do pilates (HERDMAN, 2015).

Pilates é um programa de exercícios que trabalham força, coordenação, respiração, flexibilidade, consciência corporal, concentração e postura, através de técnicas que ativam musculaturas profundas e pouco utilizadas no dia a dia. Tem comprovada eficiência na reabilitação de diversas doenças, na prevenção de lesões, melhora do condicionamento físico geral e qualidade de vida (SIQUEIRA et al., 20II).

Para Liebano (202I) o pilates é efetivo na melhora da dor lombar e no aumento da capacidade funcional, pois os exercícios vai desde um posicionamento de menor compressão articular (sem a ação da gravidade) até os movimentos funcionais e, a curto prazo já é possível se beneficiar dos seus efeitos num ambiente controlado e assistido, visto que seu método se baseia em exercícios de força, alongamento, flexibilidade e equilíbrio, proporcionando assim à diminuição da tensão dos músculos e o fortalecimento de musculatura profunda estabilizadora da coluna.

\subsubsection{Método: quiropraxia}


A quiropraxia tem como ênfase o seu envolvimento no corpo entre a estrutura (sistema musculoesquelético, a coluna vertebral e as articulações) e sua funcionalidade, na qual é comandada pelo cérebro, visto que esse envolvimento é capaz de interferir na comunicação necessária do corpo. E preocupa-se com a etiologia, patogênese, terapêutica, síndromes dolorosas e com tudo que tenha relação com a estaticidade e dinâmica do sistema neuro-músculo-esqueletal. Utilizada como forma de tratamento para a $\mathrm{HD}$ a quiropraxia tem como objetivo auxiliar a reduzir a tensão colocada sobre o disco lesionado. A mesma pode ser empregada por profissional quiropraxista cuja missão é devolver e manter a saúde ao paciente (BOTELHO et al., 2017; UCHOA, 2018).

A quiropraxia deve ser executada seguindo um padrão dividido em seis tempos: (a) localização da fixação, (b) escolha da melhor posição para o ajuste, (c) condução da articulação até sentir uma restrinção, (d) o aguardo do reflexo neurotendinoso e (d) desencadeamento da ação do ajuste através de uma manipulação rápida. Os ajustes gerais são ações direcionadas a regiões determinadas. Seu objetivo é a recuperação da mobilidade regional, cervical, torácica, lombar, pélvica e extremidade. O tempo de tratamento e duração vai depender de um diagnóstico por parte do terapeuta, no qual deverá ser feito uma anamnese e exame físico (MACHADO, 2019).

\subsubsection{Método: estabilização segmentar lombar}

Estabilização segmentar trata-se de um método de fortalecimento baseado na consciencialização da contração muscular, no treinamento resistido dos estabilizadores lombares e na estimulação proprioceptiva. A estabilização segmentar lombar foca a hierarquia muscular, dividindo o sistema em músculos profundos (estabilidade segmentar), superficiais tônicos (antigravitários) e superficiais produtores de movimento (CARVALHO, 2015; SIQUEIRA et al., 20II).

Segundo Ferreira (20II) essa técnica tem por finalidade diminuir o quadro doloroso, mas também minimizar ao máximo o número de recidivas. A ideia central está no controle motor dos músculos profundos do tronco e abdómen, multífido lombar e transverso de abdómen, com objetivo de facilitar as musculaturas locais de forma seletiva, enfatizando o controle intersegmentar da coluna lombar, cervical, ombro, quadril e joelhos. 
5.1o Método: Mulligan

A técnica Mulligan consiste da aplicação de movimentos acessórios na coluna vertebral e nos diferentes segmentos corporais, devendo sempre ser executada em posições antigravitacionais ou em movimento apresentando diversos benefícios, dentre eles podemos citar: alívio imediato ou diminuição da dor e melhora da biomecânica articular (SILVA et al., 2011).

O Conceito Mulligan é uma das técnicas da terapia manual que fundamenta no alinhamento normal de uma articulação resultando em aumento da flexibilidade e função. A técnica fornece subsidio diligente para um tratamento eficaz, de baixo custo ao paciente e ao terapeuta, rápido e sem muitas contra indicações. $\mathrm{Na}$ maioria dos casos, as técnicas de tratamento devem ser aplicadas em posição com o paciente de pé ou sentado, o que oferece várias vantagens: o condicionamento é mais confortável para o paciente do que dobrado ou inclinado para a frente, principalmente no caso do idoso e o paciente que apresenta dor severa e refere dificuldade no movimento sem a exacerbação da dor (GODINHO et al. 2oII; FERNANDES et al., 2ori).

\subsection{Método: Maitland}

O Conceito ou Técnica de Maitland tem como objetivo aliviar dores e liberar com segurança determinadas estruturas, e com isso restaurar os movimentos, amplitude e a mobilidade articular normal, melhorando, assim, a função do indivíduo (PIRAN; MACEDO, 2012; SANTOS, 2016).

O método Maitland é muito importante no tratamento de lombalgia, pois atuará diretamente nas causas da dor, manipulando articulação e tecidos, devolvendo assim a fisiologia o mais perto possível do normal, e acelerando o processo de auto cura do corpo humano (PERFEITO; MARTINS, 2020).

\subsubsection{Método: controle postural}

O controle postural é um aspecto básico para compreender a capacidade que o ser humano tem para exercer suas atividades e manter o corpo em equilíbrio em situações de repouso (LEMOS, 2013). 
A boa postura é um dos requisitos que ganha destaque quando o tema é a prevenção, a manutenção ou a recuperação da saúde e do bem-estar corporal. Além do conhecimento e o controle sobre a postura são instrumentos de poder úteis tanto para disciplinar os corpos, impondo normas e regras, como para libertá-los, expondo-lhes suas possibilidades e fazendoos refletir nas normas e regras vigentes. Devemos, então, estar atentos à forma que esses conhecimentos são apresentados e utilizados nas definições de boa postura. $O$ controle postural pode ser adquirido com exercícios praticados em diversas áreas de saúde e bem estar como academias, balé, RPG (Reeducação Postural Global) e outros (CANDOTTI, 20II; SIQUEIRA, 20II).

\subsubsection{Método: tração vertebral}

A tração da coluna vertebral é um procedimento utilizado para tratar e aliviar os sintomas de várias condições clínicas da coluna vertebral causados por redução do espaço intervertebral e sobrecarga de outras estruturas. $\mathrm{O}$ objetivo da tração é produzir uma força de separação sobre os discos intervertebrais para agir contra a diminuição causada pela carga de compressão, e restaurar o seu funcionamento mecânico, aliviando assim os sintoma (SOUZA et al., 2oII).

É uma poderosa ferramenta para o reposicionamento articular e a liberação da compressão nervosa evitando assim, em um grande número de casos, uma intervenção cirúrgica, o método funciona da seguinte forma: uma cinta acoplada à máquina é colocada no paciente, proporcionado uma tração na região da hérnia. O paciente permanece deitado durante o trabalho de descompressão. O fisioterapeuta vai identificar o disco lesado e programar a máquina para efetuar a tração na medida e no local. $\mathrm{O}$ equipamento aplica exatamente a tensão necessária para a abertura entre uma vértebra e outra sem submeter a área ao risco de lesão (CARVALHO, 2015).

Com esse método, a possibilidade de que o descolamento do disco intervertebral seja amenizado é maior do que nos tratamentos convencionais, pois a descompressão é realizada diretamente no disco afetado, por proporcionar a separação dos corpos vertebrais, possibilitando um aumento de fluxo de líquido nas estruturas capsulares, melhorando a nutrição dos discos intervertebrais. Os demais tratamentos costumam tratar a hérnia 
indiretamente. Mesmo que esta amenização não ocorra, o paciente, em geral, tem melhora completa das dores na região afetada. Porém, não é recomendado para pessoas que tenham osteoporose severa, pacientes com suspeita de fratura de bacia, comprometimento intraabdominal e ainda para pessoas que tenham instabilidade articular severa (KISNER; COLBY, 2016).

\section{CONSIDERAÇÕES FINAIS}

Uma grande parcela da população nos dias de hoje, convive com dores na coluna vertebral, resultado de má postura, sedentarismo, execução errada de exercícios entre outros fatores. Entretanto a fisioterapia convencional pode auxiliar no quadro álgico do paciente, através das técnicas fisioterapêuticas, como estabilização segmentar lombar, pilates, acupuntura entre outros.

Através de estudos citados e pesquisador nessa revisão, conclui-se que a hérnia discal é uma patologia a qual afeta a estrutura do anel fibroso, responsável por auxiliar na mobilidade e amortecer impactos sobre a coluna, o tratamento conservador aplicado com o auxílio de um diagnóstico precoce tem uma probabilidade maior de resultados satisfatórios, dispensando a intervenção cirúrgica. Porém, o tratamento escolhido dependerá de cada situação apresentada.

O fisioterapeuta deverá conhecer a anatomia e fisiologia da coluna vertebral e discos e a fisiopatologia da hérnia discal, pois são nessas informações que se baseiam toda a abordagem fisioterápica. Ao seguir o tratamento da forma correta, o paciente com hérnia de disco pode realizar suas atividades diárias sem maiores prejuízos e com mais qualidade de vida.

\section{REFERÊNCIAS}

ALECRIM, A. Artigo: método Mackenzie - o que é? - tratamento de dores agudas e crônicas da coluna vertebral. 2014 .

ALVES, V. L. S; MEVES, R. Fisioterapia nas lesões da coluna vertebral. I. ed., São Paulo: Atheneu, 2014. I20 p.

BARBOSA, R. I.; SILVA, M. F. Fisioterapia traumato-ortopédica. I. ed.; Porto Alegre: Artmed, 2021. 264 p. 
BORTOLAZZO, G. L.; et al. Efeitos da manipulação cervical alta sobre a atividade eletromiográfica dos músculos mastigatórios e amplitude de movimento de abertura da boca em mulheres com disfunção temporomandibular: ensaio clínico randomizado e cego. Fisioterapia e Pesquisa, Piracicaba/SP, v. 22, n. 4, p. 426-434, 2015.

BOTELHO, M. B., et al. Terapia manipulativa da coluna vertebral e melhoria do desempenho esportivo: uma revisão sistemática. Journal of manipulative and physiological therapeutics, v. 40, n. 7, p. 535-543, Doi: 10.1016 - j.jmpt., 2017.

BRANCO, A. Q. P. C. Efeitos da mobilização neural sobre a dor, força muscular e amplitude de movimento: revisão de literatura. Saúde em Revista, Piracicaba, v. 18, n. 50, p. 77-83, set./dez. 2019 .

BUTLER, D. S. Mobilização do Sistema Nervoso. I. ed.; Barueri (SP): Manole, 2015. 265 p.

CAIRES, L. M; ALVES, F. Degeneração do disco intervertebral: revisando conceitos. Revista NBC. São Paulo, v. 6, n. 16, p. 46-59, 2018.

CANÇADO, J. Do-in: a milenar arte chinesa de acupuntura com os dedos. I. Ed.; São Paulo: Ground, 2017. $320 \mathrm{p}$.

CANDOTTI, Cláudia Tarragô; ROHR, Jóice Elisa; NOLL, Matias. A Educação Postural como conteúdo curricular da Educação Física no Ensino Fundamental II nas escolas da Cidade de Montenegro/RS. Movimento(ESEF/UFRGS), v. 17, n. 3, jul/set. 2011.

CARLOS, E. P. F. Abordagem fisioterapêutica no tratamento de hérnia de disco. 2. ed.; Rio de Janeiro: Guanabara Raogan e Editoria, 20II. 424 p.

CARVALHO, A. S. Sistema de avaliação e tratamento da coluna lombar com o uso de tração mecânica. 2015. 72 f. Tese (Doutorado em Engenharia Mecânica), Universidade Estadual Paulista. Faculdade de Engenharia de Guaratinguetá, Guaratinguetá, 2015. Disponível em: 〈http://hdl.handle.net/II449/I23293〉. Acesso emI5 de set. 2021.

COELHO, S. S.; CORDEIRO, O. D.; VIDOTTO, J. J. Tratamento hidroterapêutico em paciente com hérnia de disco lombar. Nova Fisioterapia, Rio de Janeiro, 2012. Disponível em: 〈https://www.novafisio.com.br/tratamento-hidroterapeutico-em-paciente-comhernia-de-disco-lombar/>. Acesso em: 04/ro/202I.

FERREIRA, D. F. A. Eficácia da estabilização segmentar nas lombalgias. 201ı. 38 f. TCC (Graduação em Fisioterapia), Centro de Ciências Biológicas e da Saúde, Universidade Estadual da Paraíba, Campina Grande, 2orı.

GODINHO, A. C. S; CORDEIRO, K. R. B; COIMBRA, D. N. Efeito terapêutico do alongamento e tração manual da coluna com protusão discal lombar na fase crônica. Revista Fisioterapia em Movimento, v. 2I, n. I, p. I05-II4, jan/mar, 201 . 
HARRISON, D. E .; OAKLEY, P. A. A tração de extensão lombar alivia os sintomas e facilita a cura da hérnia / sequestro de disco em 6 semanas, após falha no tratamento de três quiropráticos anteriores: relato de caso $\mathrm{CBP}^{\circledR}$ com 8 anos de acompanhamento. Journal of Physical Therapy Science, v. 29, n. II. p. 2051-2057, 2017.

HERDMAN, A. Guia completo de pilates. I. ed., São Paulo: Pensamento, 2015. 256 p.

JAKAITIS, F. et al. Reabilitação aquática. I. ed., São Paulo: Editora Manole, 2016. 296 p.

KISNER, C.; COLBY, L. A. Exercícios terapêuticos: fundamentos e técnicas. $6^{a}$ ed. Barueri: Manole, 2016. I168 p.

KUTZKE, J. L et al. Métodos fisioterapêuticos aplicados em pacientes com hérnia de disco lombar: um estudo de revisão da literatura. Revista Eletrônica Multidisciplinar Facear, v. 9, n. I, p. 26-35, Bionorte, Montes Claros, jan./jun. 2016.

LEMOS, L. F. C. Desenvolvimento do equilíbrio postural e desempenho motor de crianças de 4 aos ro anos de idade. 2013. 96 p. Dissertação (Mestrado em Educação Física) Universidade de Brasília, Brasília, 2013.

LIEBANO, R. E. Eletroterapia aplicada à reabilitação: dos fundamentos às evidências. I. ed. Rio de Janeiro: Revinter, 2021. 190 p.

LOIOLA, G. M. L. V et al. Terapia manual em pacientes portadores de hérnia discal lombar: revisão sistemática. Ciência em Movimento Reabilitação e Saúde. v. 19, n. 38, p. 89-97, 2017.

LOPES, R. S. D et al. Influência do alongamento muscular e da mobilização neural sobre a força do músculo quadríceps. ConScientia e Saúde, v. 9, n. 4, p. 603-9, 2011.

MACHADO, M. P. Método Francois Soulier quiropraxia instrumental. I. ed., São Paulo: Livraria e Andreoli, 2019. 224 p.

MENDONÇA, E. M. T; ANDRADE, T. M. Método Mckenzie como protocolo de tratamento em hérnia de disco lombar. Revista Interdisciplinar, v. 9, n. 3, p. 130-137, jul. ago. set. 2016.

NORDIN, M; FRANKEL, V. H. Biomecânica básica do sistema musculoesquelético. 4. ed. Rio de Janeiro: Guanabara Koogan, 2014. 412 p.

NUNES, V. R. H. Avaliação do equilíbrio espinopélvico dos pacientes com espondilolistese degenerativa $\mathrm{L}_{4}$ - $\mathrm{L}_{5}$ e hérnia de disco $\mathrm{L}_{4}$ - $\mathrm{L}_{5}$ submetidos a cirurgia. Revista Brasileira de Ortopedia, v. 5I, n. 6, p. 662-666, 2016.

OLIVEIRA, A. S. B.; ODA, A. L. Reabilitação em doenças neuromusculares - guia terapêutico prático. I. ed., São Paulo: Ed. Atheneu, 2015. 416 p. 
OLIVEIRA, E. M. et al. Tópicos especiais em fisioterapia aquática. I. ed., Pernambuco: Fundação Antônio Santos Abranches - FASA, 2019. 264 p.

PEREIRA, M. F. G. Identificação humana através das particularidades ósseas no exame radiográfico da coluna vertebral e tórax. 2018, I66 f. TCC (Mestrado em Medicina Legal), Instituto de Ciências Biomédicas Abel Salazar da Universidade do Porto, Portugal, 2018.

PERES, C.; RISSO, L; OLIVEIRA, L. U. Efeitos da manipulação do ilíaco na descarga de peso no retropé em indivíduos com disfunção sacro-ilíaca. Revista Terapia Manual, v. 9, n. Io 42 , p. 150-4, 2011 .

PERFEITO, R. S.; MARTINS, E. Hérnia de disco lombar: etiologia, diagnóstico e tratamentos mais utilizados. Perspectiva: Ciência e Saúde, Osório, v. 5, n. 3, p. 58-65, dez. 2020.

PINTO, S. Diagnóstico cinético funcional e imaginologia: membros inferiores e coluna vertebral. I. ed.; Londrina: Editora e Distribuidora Educacional S.A., 2016. 196 p.

PIRAN, M.; MACEDO, S. Análise comparativa do tratamento da dor lombar crônica utilizando-se as técnicas de Maitland, Mulligan e Estabilização Segmentar. EFDeportes.comRevista Digital. Buenos Aires, v.17, n.17o, Julio de 2012. Disponível em: 〈http://www.efdeportes.com/ >. Acesso em: 13/o8/2021.

POWERS, S. K.; HOWLEY, E. T. Fisiologia do exercício: teoria e aplicação ao condicionamento e ao desempenho. 9. ed., São Paulo: Manole, 2017. 672 p.

PUDLES, E.; DEFINO, H. L. A. A coluna vertebral: conceitos básicos. I. ed., Porto Alegre: Artmed, 2014. $369 \mathrm{p}$.

SANTOS, J. P. M. Ciências morfofuncionais do aparelho locomotor: membros inferiores e coluna vertebral. I. Ed.; Londrina: Editora e Distribuidora Educacional S.A., 2018. 192 p.

SANTOS, M. L. B. Efeitos da técnica de Maitland no tratamento da lombalgia crônica: uma revisão bibliográfica. 20I6. I3 p. Artigo (Pós-graduação em Traumato Ortopedia com Ênfase em Terapia manual), Faculdade Ávila, Goiânia - GO, 2016.

SCHOELLER, S. D. et al. Abordagem multiprofissional em lesão medular: saúde, direito e tecnologia. I. ed.; Florianópolis: Publicação do IFSC, 2016. 304 p.

SILVA, G. R. et al. Efeito de técnicas de terapias manuais nas disfunções craniomandibular. Revista Brasileira de Ciências da Saúde, v. I, n. I, p. I7-22, Jul/Dez, 201 I.

SIQUEIRA, G. R. et al. Alterações posturais da coluna e instabilidade lombar no indivíduo obeso. Fisioterapia em Movimento, Curitiba, v. 24, n. 3, p. 557-566, jul./set. 2011.

SOUSA, J. P. L.; SILVA, A. M. Tratamento de lombalgias: lombalgias e técnicas de estabilização segmentar. I. ed., Rio de Janeiro: Novas Edições Acadêmicas, 2019. 72 p. 
SUSSELA, A. O et al. Hérnia de disco: epidemiologia, fisiopatologia, diagnóstico e tratamento. Acta Méd, Porto Alegre, v. 38, n. 7, 2017. Disponível em $\langle$ https://docs.bvsalud.org/biblioref/2018/o5/883477/hernia-de-disco-final_rev.pdf〉 Acesso em: $18 / 10 / 2021$.

UCHOA, C. C. et al. Quiropraxia: abordagem fisioterapêutica associada ao tratamento de hérnia discal lombar. Revista Acadêmica, v. 3, n. I, 2018.

VIEIRA, A. L. T. Diagnóstico de hérnia de disco da coluna lombar em ressonância magnética. Revista JRG de Estudos Acadêmicos, ano IV, vol. 4, n. 8, jan./jun. 202I.

WEN, T. S. Acupuntura Clássica Chinesa. 15. ed.; São Paulo: Wltrix, 2011. 248 p.

YAMAMURA, Y.; YAMAMURA, M. Guia de Acupuntura. I. ed.; São Paulo: Manole, 2015. $868 \mathrm{p}$. 